\author{
К.Є. Золотько, Д.В. Красношапка \\ Дніпровський наиіональний університет імені Олеся Гончара
}

\title{
ФОРМУВАННЯ БАЗИ ЗНАНЬ ЕКСПЕРТНОЇ СИСТЕМИ ПРОЕКТУВАННЯ ГЕЛІОСИСТЕМ
}

Робота присвячена формуванню бази знань експертної системи проектування геліосистем. Розглянуто математичні моделі геліосистем різних типів та надходження сонячної енергії, які є основою бази знань такої експертної системи. Розглянуто алгоритми визначення кількості енергії, що надходить від різного типу геліосистем. Наведено якісні та кількісні характеристики, які с основою такої бази знань.

Ключові слова: експертна система, база знань, математична модель геліосистеми, електрична та теплова енергія.

\author{
K.Y. Zolotko, D.V. Krasnoshapka \\ Oles Gonchar Dnipro National University
}

\section{FORMATION OF THE KNOWLEDGE BASE OF THE EXPERT SYSTEM OF SOLAR SYSTEMS DESIGN}

The size of Ukraine's annual losses from environmental degradation are currently estimated by the International Institute of Environmental Management (Switzerland) at 35\% of gross national income. The biggest source of ambient air pollution is the energy sector.

This is mainly due to the use of fossil fuels in traditional energy systems. New technologies in them increase the efficiency of energy carriers, but do not radically improve the ecological situation. At the present stage of society development the issue of rational use of energy resources becomes especially acute, which is caused by the depletion of fossil fuel reserves, environmental pollution, public aversion to nuclear energy.

In this regard, the use of clean renewable energy sources and, above all, the energy of the sun, becomes urgent. Almost all unconventional energy is the transformation and use of solar energy in various ways. According to existing estimates, about $15 \%$ of all solar energy on Earth can be used without the threat of ecological damage to the environment. The difficulty in harnessing solar energy for production is due to the low flux density, low temperature levels and cyclicality of the influx. Therefore, for its further use, it is necessary to apply concentrators and energy transformers, or to select consumers who need low-potential heat.

The work is devoted to the formation of a knowledge base of an expert system for the design of solar systems. The mathematical models of solar systems of different types and solar energy inputs, which are the basis of the knowledge base of such an expert system, are considered.

The algorithms of determining the amount of energy coming from different types of solar systems are considered. The qualitative and quantitative characteristics which are a basis of such knowledge base are resulted.

Key words: expert system, knowledge base, mathematical model of solar system, electric and thermal energy.

(C) Золотько К.С., Красношапка Д.В., 2021 


\section{ФОРМИРОВАНИЕ БАЗЫ ЗНАНИЙ ЭКСПЕРТНОЙ СИСТЕМЫ ПРОЕКТИРОВАНИЯ ГЕЛИОСИСТМ}

Работа посвящена формированию базы знаний экспертной системы проектирования гелиосистем. Рассмотрены математические модели гелиосистем различных типов и поступления солнечной энергии, которые являются основой базы знаний такой экспертной системы. Рассмотрены алгоритмы определения количества энергии, поступающей от разного типа гелиосистем. Приведены качественные и количественные характеристики, которые являются основой такой базы знаний.

Ключевые слова: экспертная система, база знаний, математическая модель гелиосистемы, электрическая и тепловая энергия.

Вступ. Питанням розрахунку та проектування систем енергопостачання нині приділяється все більша увага. Пов'язано це із виснаженням традиційних джерел енергії, їх подорожчанням та проблемами забруднення навколишнього середовища. Тому виникає необхідність раціонального використання традиційного палива та широкого застосування нетрадиційних джерел (геліосистеми, вітроагрегати, хвильові електростанції тощо).

Найбільшого поширення зараз набули сонячні системи енергопостачання. При зовнішній простоті слід враховувати, що такі системи вимагають великих капітальних витрат при їх створенні та значних засобів для підтримки працездатності. Крім того, вони значною мірою залежать від місця розташування та кліматичних умов. Так, наприклад, на одній і тій же широті, але в різних регіонах можуть значно відрізнятися температура навколишнього середовища, швидкість вітру, запиленість та хмарність. Це значною мірою вплине на ефективність геліосистем, терміни їхньої окупності та працездатність.

Існує велика різноманітність геліосистем, які дозволяють виробляти електроенергію та теплову енергію. Наприклад, для вироблення електрики можуть застосовуватись:

- фотоперетворювачі;

- геліосистеми із турбомашинами;

- геліосистеми на основі двигуна Стірлінга;

- геліосистеми із термоелектричними елементами.

Для отримання тепла можливе використання:

- фотоперетворювачів;

- колекторів із концентраторами сонячної енергії;

- геліосистем із природно конвекцією;

- Плоских сонячних колекторів;

- пасивні геліосистеми

- Вакумурованих плоских сонячних колекторів.

Постановка задачі. Таким чином, для проектування геліосистем необхідно насамперед визначитися з їі типом. Як показує аналіз літературних джерел 88 
$[1,3,4]$, розрахунок тих чи інших геліосистем є досить тривалим і складним процесом, який враховує безліч додаткових параметрів. Наприклад, коефіцієнти хмарності, запиленості, кута нахилу та орієнтації геліоколектора тощо. Тому створення експертної системи для цих цілей дозволяє значно скоротити час проектування, поліпшити вибір і підвищити точність розрахунків.

Одним із основних елементів експертної системи є база знань. В даному випадку база знань повинна містити математичні моделі процесів та елементів геліосистем.

Методи розв'язання. В основі розрахунків усіх сонячних геліосистем лежить щільність сонячної радіації, що припадає на освітлену поверхню. При цьому в базі знань експертної системи повинна бути модель щільності сонячного випромінювання, що припадає на похилу поверхню. Вона включає табличні дані, взяті з кліматичних довідників [5], та їх апроксимація $[1,3]$.

$$
E_{H}=\left\{\begin{array}{l}
E_{m} R_{c} \sin \left(\pi \frac{\tau}{\tau_{c}}\right), \quad \text { при } \tau_{\mu} \leq \tau \leq \tau_{\kappa} \\
0 \quad \text { при } \tau \prec \tau_{н} u \tau \succ \tau_{\kappa}
\end{array}\right.
$$

де $\mathrm{E}_{\mathrm{m}}$-максимальне значення інтенсивності сонячної радіації, що припадає на горизонтальну поверхню;

$\mathrm{R}_{\mathrm{c}}$-середньодобовий коефіцієнт перерахунку сонячної радіації, що припадає на похилу поверхню $[1,3]$;

$\tau$-час, що відраховується з моменту сходу Сонця;

$\tau_{\mathrm{H}}, \tau_{\mathrm{\kappa}}$ - Момент початку та закінчення освітлення сонячного колектора;

$\tau_{\mathrm{c}}$-тривалість світлового дня.

Для фотоелектричних перетворювачів база знань включає залежність ККД від типу фотоперетворювачів. Наприклад, для фотоперетворювачів на основі кремнію становить $14 \%$, а для сонячного елемента 3 перовскіту та кремнію - 29\%. Причому ККД залежить від часу експлуатації, температури та забрудненості поверхні.

$$
Q=\eta_{\phi} \eta_{3} \psi_{c} \int_{\tau_{u}}^{\tau_{k}} E_{h} d \tau,
$$

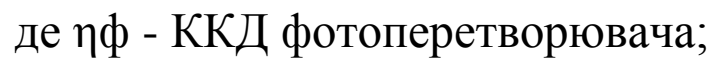

$\eta_{3}$ - ккд забруднення;

$\psi_{c}$ - коефіцієнт сонячного сяйва.

Крім фотоперетворювачів у такі системи також входять перетворювачі та акумулятори. Математичні моделі їх роботи можна знайти в спеціальній літературі або просто врахувати як коефіцієнт, який зменшує кількість енергії, що надходить.

Іншими системами, які зараз знаходять широке застосування, $\epsilon$ геліосистеми з вимушеним рухом теплоносія і плоскими сонячними колекторами. Схема такої геліосистеми представле на рис.1. 
Основними елементами, що визначають ефективність роботи системи $є$ тепловий акумулятор та геліоколектор. У геліоколекторі відбувається поглинання падаючої сонячної енергії та іiї перетворення на теплову енергію нагрітого теплоносія. Так само в контурі геліоколектора може бути встановлений теплообмінник, який дозволяе використовувати різні теплоносії тепловому акумуляторі та плоскому сонячному колекторі. Це дозволяє застосовувати незамерзаючийтеплоносій і тому цілий рік експлуатувати такі установки.

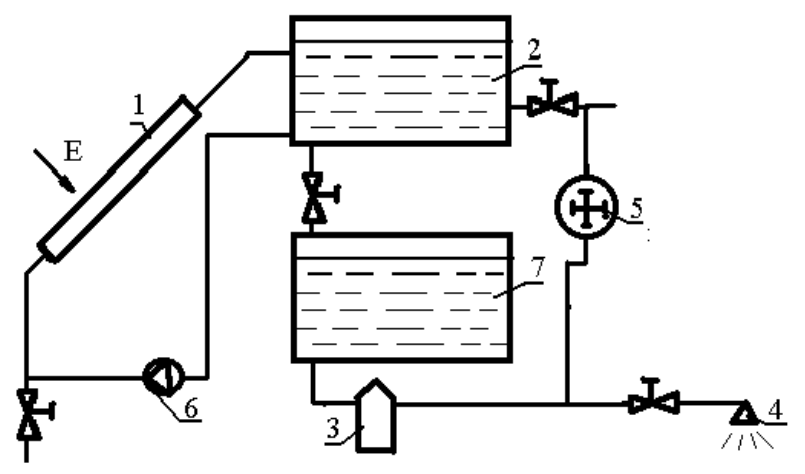

Рис. 1. Схема геліоустановок з вимушеним рухом теплоносія

1- геліоколектор; 2- тепловий акумулятор; 3-догрівач; 4-споживач;

5- змішувач; 6 - циркуляційний насос; 7 - бак споживання.

У загальному випадку кількість енергії, що надходить від такої установки, можна визначити 3 наступного співвідношення:

$$
Q=\psi \int_{\tau_{\mu}}^{\tau_{\kappa}} G_{T H} \cdot c_{T H} \cdot\left(t_{p}-t_{a}\right) \cdot J_{N} d \tau,
$$

де $G_{T H}$ - витрата теплоносія в контурі геліколектора;

$c_{T H}$ - питома теплоємність теплоносія;

$t_{a}$ - температура теплоносія у тепловому акумуляторі;

$t_{p}$ рівноважна температура;

$$
\begin{aligned}
& J_{N}=\frac{2 \cdot N_{T O} \cdot\left(1-e^{-N_{\Gamma K}}\right)}{2 \cdot\left(1-e^{-N_{I K}}\right)+N_{T O} \cdot\left(1+e^{-N_{I K}}\right)} ; \\
& N_{T O}=\frac{K_{T O} \cdot F_{T O}}{G_{T H} \cdot c_{T H}} ; N_{I K}=\frac{K_{I K} \cdot F_{I K}}{G_{T H} \cdot c_{T H}}
\end{aligned}
$$

$K_{\Gamma K}, K_{T O}$ - коефіцієнти теплових втрат геліоколектора та теплового акумулятора;

$F_{\Gamma K}, F_{T O}$ - площа геліоколектора та теплового акумулятора;

рівноважна температура

$$
t_{p}=\frac{\gamma_{\Gamma K}}{K_{\Gamma K}} \cdot E_{н}+t_{н c}
$$

де $\gamma_{\Gamma к}$ - коефіцієнт сприйняття сонячної енергії; 
$t_{н с}$ - температура навколишнього середовища.

У разі коли такі установки використовуються для отримання електроенергії, необхідно врахувати коефіцієнт перетворення теплової енергії в електричну, який залежить від типу перетворювача.

Ще одним із поширених типів геліостистем є системи 3 природною циркуляцією теплоносія (рис.2).

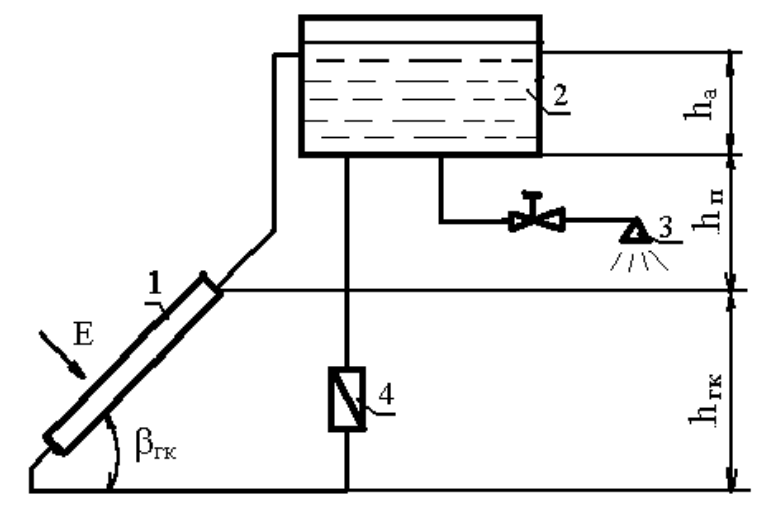

Рис. 2. Схема геліоустановки 3 природною циркуляцією теплоносія 1- геліоколектор; 2- тепловий акумулятор; 3-споживач; 4- зворотний клапан; 5-теплообмінник.

Розрахунок таких геліосистем ускладнюється визначенням гідравлічного опору трубопроводів у контурі геліоколектора. Якщо воно виявиться надто високим, то природна конвекція може не настати і система не працюватиме. Тому перед проведенням проектування геліосистем у базі даних експертної системи повинні утримуватися відомості про гідравлічні опори різних типів $\mathrm{i}$ моделей геліоколекторів, які дозволили на етапі вибору типу геліоустановки встановити можливість ії функціонування.

Кількість енергії, що надходить від такої установки, можна визначити 3 наступного співвідношення

$$
Q=\psi_{c} \int_{\tau_{H}}^{\tau_{\kappa}} c_{T H} \cdot\left(t_{p}-t_{a}\right) \cdot \Phi_{N} \cdot G_{T H} d \tau,
$$

де $\Phi_{N}=1-e^{-N_{\Gamma \kappa}}$

Такі установки знаходять широке поширення за рахунок простоти конструкції та можливості їх використання у разі відсутності електрики, яка потрібна, у попередньому випадку, для роботи насоса. Проблеми з їх експлуатацією пов'язані з необхідністю ретельного проектування дотримання всіх умов існування вільної конвекції. Такі установки проблематично використовуватиме електроенергії, т.к. температура теплоносія на виході суттєво змінюється протягом доби та їі складно регулювати, а, отже, і складно експлуатувати разом 3 ними спеціальні перетворювачі тепла на електрику.

Найчастіше, поряд із фотоперетворювачами, для вироблення електроенергії використовують геліосистеми із концентраторами (рис.3.). У таких систе- 
мах сонячне випромінювання, яке не має високої щільності (до 1 кВт/м² опівдні на екваторі) за допомогою спеціальних відбивачів концентрується на теплоприймачі, що дозволяє досягти високих температур і використовувати турбомашинні перетворювачі за циклом Ренкіна, Брайтона або Стірлінга.

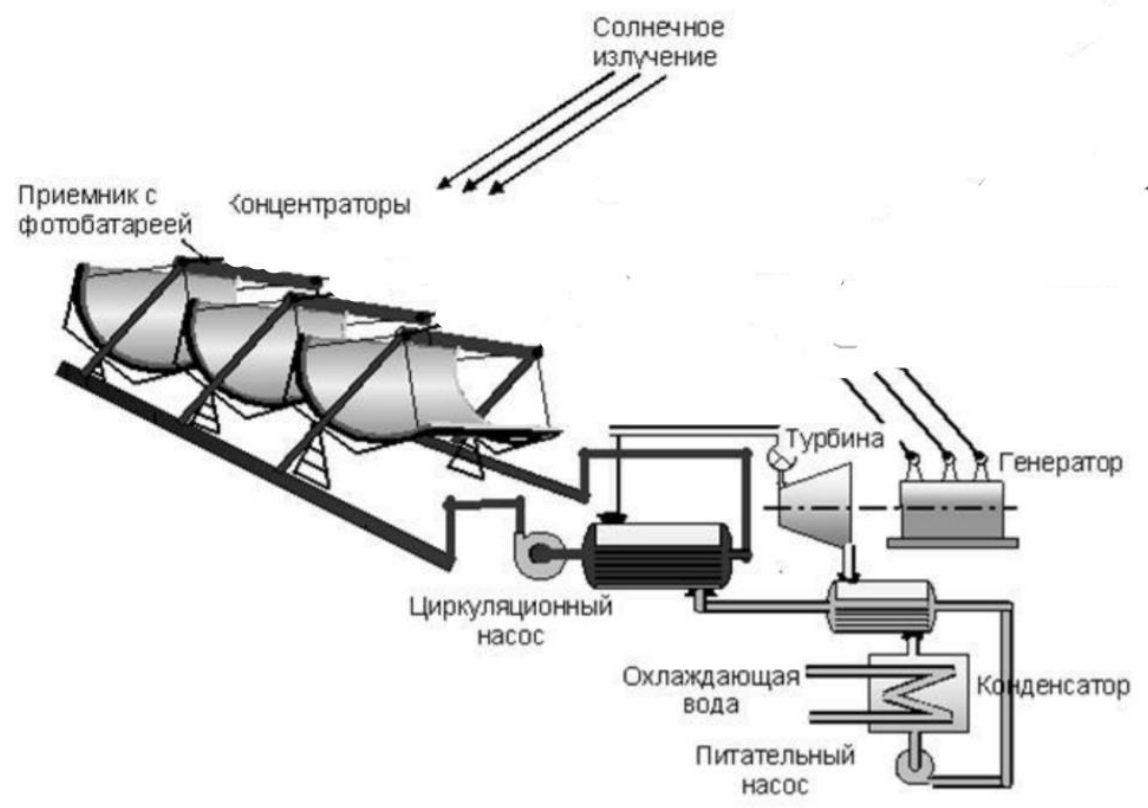

Рис.3. Геліосистеми із концентраторами сонячної енергії.

Кількість енергії, що отримується в таких системах, можна визначити за допомогою співвідношення

$$
Q=\eta_{u} \eta_{n} \psi_{c} \int_{\tau_{\mu}}^{\tau_{\kappa}} E_{H} d \tau,
$$

де $\eta_{u}$ - ККД термодинамічного циклу; $\eta_{n}$ - ККД системи «концентратор приймач».

Такі геліосистеми мають більш високий ккд, ніж фотоелектричні. Але вони вимагають і вищих капітальних витрат за виробництво і видатків на експлуатацію. Тому, як правило, геліосистеми з концентраторами використовують у сонячних електростанціях великої потужності. При цьому концентратори можуть являти собою профільовані дзеркала, так і звичайні плоскі відбивачі. Роботою таких плоских відбивачів зазвичай керує спеціальне обладнання.

Аналіз результатів. Таким чином, основу бази знань експертної системи проектування геліосистем представляють математичні моделі, що були розглянуті вище. Крім цих моделей необхідно врахувати низку факторів та оцінку цих факторів, і вибір типу геліосистеми мають давати фахівці. Наприклад, коли йдеться про гаряче водопостачання в літні місяці в місцях із недоліками електроенергії, то перевага явно буде віддана геліосистемам із природною циркуляцією. Також необхідно враховувати, що геліосистеми (особливо 3 фотоелектричними перетворювачами) потребують значних площ та відповідної орієнтації. 
На рис.4 представлена схема бази знань експертної системи, що дозволяє проводити попередній вибір типу геліосистеми.

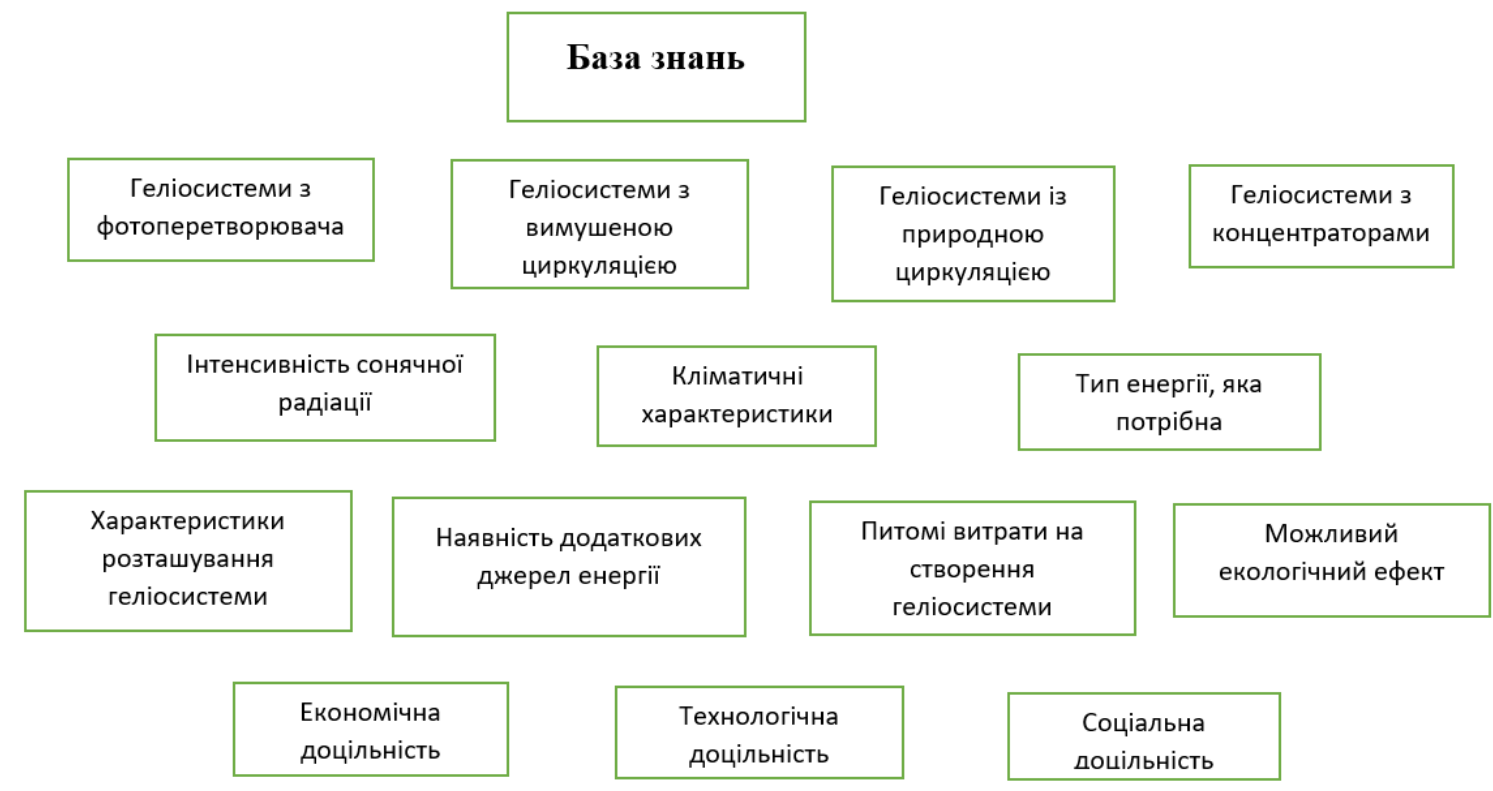

Рис.4. Схема бази знань експертної системи

Як видно з цієї схеми, крім математичних моделей, в базі знань існує безліч параметрів, які мають якісний характер і визначити їх кількісні оцінки здатні лише фахівці.

Висновки. Геліосистеми $є$ перспективним напрямом розвитку сучасної енергетики. Проте, їх проектування та впровадження потребує значних тимчасових та матеріальних ресурсів. Тому створення експертних систем допоможе значно скоротити ці витрати. Основою будь-якої експертної системи $є$ основа знань. У цій експертній системі база знань повинна бути конгломератом математичних моделей геліосистем та їх розрахунків, їх якісних характеристик, а також якісних і кількісних характеристик місцевості, де передбачається впровадження таких систем.

\section{Бібліографічні посилання}

1. Даффи Дж. А., Бекман У.А. Тепловые процессы с использованием солнечной энергии. М.: Мир, 1977. - 420 c.

2. Михеев М.А., Михеев И.М. Основы теплопередачи. М.: Энергия, 1973. 320 с.

3. Сиворакша В.Е., Золотько К.Е., Марков В.Л., Петров Б.Е. Гелиосистемы для отопления и горячего водоснабжения.: Учебное пособие. - Днепропетровск: ДГУ, 1995. 196 с.

4. Сиворакша В.Е., Золотько К.Е., Марков В.Л., Петров Б.Е. Влияние конструкции тепловоспринимающего элемента на эффективность работы гелиоколлектора. Экотехнологии и ресурсосбережение. 2001. №2. С.70-73.

5. Климатологический справочник СССР. Вып.10. Украинская ССР и Молдовская ССР. ч.6. Облачность и солнечное сияние. Л.: Гидрометеоиздат, 1963. 944 с.

6. Джарратано Д., Райли Г. Экспертные системы. Принципы разработки и программирование. М. :Вильямс, 2007. 560 с. 